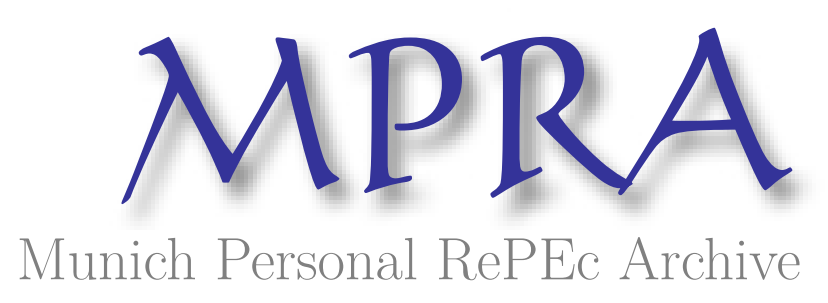

\title{
Economic education for at-risk students: an evaluation of Choices Changes
}

Grimes, Paul W.

Mississippi State University

1995

Online at https://mpra.ub.uni-muenchen.de/39885/

MPRA Paper No. 39885, posted 06 Jul 2012 22:10 UTC 


\title{
ECONOMIC EDUCATION FOR AT-RISK STUDENTS: AN EVALUATION OF CHOICES \& CHANGES
}

\author{
by Paul W. Grimes*
}

\begin{abstract}
This paper presents an evaluation of Choices \& Changes, an economics education program designed to teach "at-risk" children in elementary and junior high school that they can control their future by making wise choices and investing in themselves. Using program-specific instruments and a national sample of approximately 1600 students, a controlled experiment was conducted to determine the effect of Choices \& Changes on student learning and attitudes. The experimental data were analyzed using a simultaneous model estimated by 2SLS with correction for self-selection due to sample attrition between pre- and post-test observations. The results indicate that Choices \& Changes had a positive effect on economic understanding for each grade level examined, ceteris paribus. Significant positive effects on attitudes were found in only one of the four student groups. These findings suggest that Choices \& Changes is meeting its short-run objective of producing cognitive understanding of economic concepts and that the attitudes of at-risk students can be altered but may require additional intervention.
\end{abstract}

Choices \& Changes is an economic education program designed specifically to help "at-risk" elementary and junior high school students use economic concepts and reasoning in their decision making processes. The Choices \& Changes curriculum is integrated across four grade levels by three underlying and continuing themes:

You can make more satisfying decisions

by carefully considering costs and benefits.

You can improve your future employment options by developing your own human capital.

You are already part of the economy, and you can be an even more productive participant by learning how to invest in your own human capital. (NCEE 1989) By building on these three themes, the program teaches students that they can control their future by making wise choices and investing in themselves.

While the Choices \& Changes program was conceived for at-risk students, the developers have not attempted to narrowly define the target student population. The curriculum follows the
National Council on Economic Education's recommended "scope and sequence" for elementary economic education (Gilliard, Caldwell, et. al. 1988). Thus, the program is flexible and can be used in any classroom. However, it is intended to provide important benefits to those students who are potential dropouts, underachievers, economically disadvantaged, socially deprived, or otherwise at-risk of failing to fulfill their potential. During the past six years more than one hundred thousand students have been exposed to Choices \& Changes.

If economic education through Choices \& Changes is to be successful in helping at-risk students, at least three separate steps must be accomplished. First and foremost, Choices \& Changes must be an effective tool in teaching basic economic concepts and reasoning. The Choices \& Changes program is based on the assumption that economics has something very valuable to offer at-risk students. Thus, the overall success of the program hinges on its ability to deliver economic learning. Second, economic understanding derived from Choices \& Changes must affect students' perception of

\footnotetext{
*Associate Professor of Economics, College of Business and Industry, Mississippi State University, Mississippi State University. Mississippi State, MS 39762. Financial support for this project was provided by the National Council on Economic Education. Special thanks are due to Patricia K. Elder and Robert J. Highsmith for their administrative support. Andre Jarreau served as graduate research assistant. Additional support provided by the Division of External Affairs, College of Business and Industry, Mississippi State University. The author wishes to thank the local program coordinators and the many economic educators who made this project possible.
} 
their societal role and future potential. Specifically, new economic knowledge and reasoning are assumed to enhance student attitudes regarding their choices and ability to control their lives. Finally, changes in student behavior must result as a response to their cognitive and attitudinal adjustments. It is assumed that economic education empowers students to make more reasoned choices. For example, when students understand the importance of human capital and the opportunity cost of dropping out of school, fewer will choose to drop out. It is expected that behavioral changes may take many forms and will be both short- and long-run in nature. If the Choices \& Changes program can effectively generate these cognitive, attitudinal and behavioral responses it will fulfill its primary objectives.

The purpose of this paper is to evaluate the first two expected student outcomes of the Choices \& Changes program discussed abovecognitive learning and attitudinal changes. While the third student outcome, behavioral change, may be considered the most important, it is also the most difficult to measure. Also, behavioral change may take considerable time to manifest itself. Given that the expected behavioral responses of Choices \& Changes students are assumed to be an extension of economic learning and attitudinal enhancement, we can not expect changes in behavior without first observing cognitive and attitudinal changes. Thus, the ultimate success of Choices \& Changes relies on the program's ability to promote economic understanding and elicit positive student attitudes.

\section{Evaluation Instruments}

The Choices \& Changes program is comprised of four separate curricula. Each curriculum is a three week course designed for a target grade level audience. These four levels include; Elementary 1 (Grade 3), Elementary 2 (Grade 5), Junior High 1 (Grade 7), and Junior High 2 (Grade 9). The content of all four courses is derived from the three major themes discussed above while the sophistication of the material is dependent upon the target level. The flexibility of the Choices \& Changes materials allows the courses to be taught one grade above or below the specified target grade levels.
Given the multi-grade format of the Choices \& Changes program, evaluation of cognitive and attitudinal effects necessarily involves the utilization of specific evaluation instruments for each grade level. Thus, four separate cognitive test instruments and four separate attitude indices were developed. (Copies of the evaluation instruments briefly described below can be found in Grimes (1991)).

\section{Test on Choices and Changes}

Four level-specific versions of a Test on Choices \& Changes (TOCC) were designed to measure the cognitive impact of the program on student participants. Each version of the TOCC is comprised of twenty multiple-choice questions each with four alternative responses. Of the twenty questions, six address fundamental economic concepts contained in all levels of the Choices \& Changes program. These six core questions are common to each version of the TOCC. The remaining fourteen questions on each test deal with grade-specific curriculum content.

Questions for each version of the TOCC were developed based on the "Conceptual Theme" matrices of the Choices \& Changes Teacher Training Handbook (NCEE 1989). An extensive instrument evaluation effort that included input from teachers who had taught the Choices \& Changes curriculum previously, economic educators, and testing specialists was undertaken to insure a reliable and valid testing instrument (Grimes 1991).

Because the Choices \& Changes program asks students to learn basic economic concepts, master them, and apply them to decision making problems, the TOCC is comprised of questions from three cognitive categories; knowledge, comprehension, and application. This represents a modified Bloom taxonomy (Bloom 1956) similar to that employed by the Basic Economics Test 2nd Edition (Walstad and Robson 1990).

\section{Choices \& Changes Attitude Indices}

To evaluate changes in student attitudes, four level-specific versions of a Choices \& Changes Attitude Index (CCAI) were developed in a manner parallel to the development of the $T O C C$. Each index was constructed to measure 
students' perception of their choice-making ability and their role in the economy around them. The student attitudes measured by the $C C A I$ are those assumed to influence future behavior.

The format of the CCAI is similar to that of the Survey on Economic Attitudes (Soper and Walstad 1983). Each of the four indices is comprised of fourteen statements requiring a student response on a Likert-type scale. The five point scale runs from "Strongly Disagree" (1) to "Strongly Agree" (5). Student responses to each statement can be aggregated to determine an overall attitude score. Each index shares eight statements in common. These core statements are designed to measure attitudes associated with the underlying themes common to each level of the curriculum. The remaining six statements address level-specific attitude content.

Like the TOCC instruments, each attitude statement is based on the "Conceptual Theme" matrix for the appropriate grade level. Each version of the $C C A I$ was carefully screened and tested for reliability (Grimes 1991).

\section{Experimental Design}

School districts in nine cities nationwide participated in this evaluation-Bridgeport, Denver, Indianapolis, Milwaukee, New Orleans, New York, Richmond, St. Louis, and Savannah. In these cities, approximately 350 teachers were trained through the National Council on Economic Education's efforts and more than 13,000 students were exposed to the Choices \& Changes curriculum. In order to examine the cognitive and attitudinal effects of the program a sample of classrooms at each grade level was drawn from this population.

The evaluation sample was constructed to provide equal weighting to each of the nine cities in the population. Two Choices \& Changes classrooms were randomly chosen at each grade level in each city to be part of the evaluation sample. In addition to the Choices \& Changes classrooms, one teacher at each grade level in each city who was not participating in the program was recruited to provide control classrooms for comparison. The absolute impact of the program on students could thus be measured by analyzing test results across
Choices \& Changes and non-Choices \& Changes classrooms.

All teachers of classes in the sample were provided with copies of the appropriate TOCC and $C C A I$ instruments and computer scorable response sheets. The Choices \& Changes teachers were instructed to administer the evaluation instruments within a standard testing environment using a pre-course/post-course design. Approximately three weeks (the intended length of the Choices \& Changes courses) after initially completing the instruments, students in the control classes were given the TOCC and CCAI a second time. Thus, "pre" and "post" observations were also made of the non-Choices \& Changes students. Additional data on classroom demographics and implementation procedures were also collected from each teacher.

The pre-course/post-course design with treatment and control groups allows for the estimation of the impact of Choices \& Changes on student learning and attitudinal response. The means and standard deviations in pre-course and post-course-scores are reported for each group in Tables 1 and 2. Standard t-tests, testing the null hypothesis that post-course scores are equal to pre-course scores, reveal that statistically significant improvements in the mean total TOCC and CCAI scores occur for each of the treatment groups in the sample described above. In general, larger improvements are found at the lower grade levels for the Choices \& Changes students. No significant positive differences in the mean total scores are observed for any of the control groups. While such findings may be indicative of a successful program, analysis of mean scores fails to account for any differences other than treatment across groups. To go beyond simple statistical comparison of mean pre- and post-course scores, an educational production function that allows for the simultaneous determination of cognitive and attitudinal response while controlling for differences in student endowments, demographic characteristics, and classroom implementation of the program was developed and estimated.

\section{The Empirical Model}

Within the framework of the standard educational production function approach (Becker and 
TABLE 1

TOCC Scores, Mean Correct by Level and Group

\begin{tabular}{|c|c|c|c|c|c|c|c|c|c|c|c|c|}
\hline & \multicolumn{3}{|c|}{ ELEMENTARY I } & \multicolumn{3}{|c|}{ ELEMENTARY II } & \multicolumn{3}{|c|}{ JUNIOR HIGH I } & \multicolumn{3}{|c|}{ JUNIOR HIGH II } \\
\hline & Pre & Post & t-value & Pre & Post & t-value & Pre & Post & $\mathrm{t}$-value & Pre & Post & t-value \\
\hline & \multicolumn{12}{|c|}{ CHOICES \& CHANGES } \\
\hline Core & $\begin{array}{c}2.93 \\
(1.39)\end{array}$ & $\begin{array}{c}4.16 \\
(1.44)\end{array}$ & 9.36 & $\begin{array}{c}3.35 \\
(1.11)\end{array}$ & $\begin{array}{c}3.95 \\
(1.19)\end{array}$ & 5.99 & $\begin{array}{c}3.65 \\
(1.05)\end{array}$ & $\begin{array}{c}3.99 \\
(1.11)\end{array}$ & 3.57 & $\begin{array}{c}3.94 \\
(1.08)\end{array}$ & $\begin{array}{c}4.35 \\
(1.15)\end{array}$ & 3.99 \\
\hline Level-Specific & $\begin{array}{c}6.19 \\
(2.57)\end{array}$ & $\begin{array}{c}9.37 \\
(2.42)\end{array}$ & 13.51 & $\begin{array}{c}6.71 \\
(2.70)\end{array}$ & $\begin{array}{c}8.13 \\
(3.15)\end{array}$ & 5.62 & $\begin{array}{c}6.66 \\
(2.34)\end{array}$ & $\begin{array}{c}8.10 \\
(2.84)\end{array}$ & 6.32 & $\begin{array}{c}8.54 \\
(2.52)\end{array}$ & $\begin{array}{c}9.62 \\
(2.90)\end{array}$ & 4.33 \\
\hline Total & $\begin{array}{c}9.12 \\
(2.98)\end{array}$ & $\begin{array}{l}13.53 \\
(4.45)\end{array}$ & 13.32 & $\begin{array}{l}10.06 \\
(3.26)\end{array}$ & $\begin{array}{l}12.08 \\
(3.84)\end{array}$ & 6.59 & $\begin{array}{l}10.31 \\
(2.78)\end{array}$ & $\begin{array}{l}12.09 \\
(3.34)\end{array}$ & 6.61 & $\begin{array}{l}12.48 \\
(3.04)\end{array}$ & $\begin{array}{l}13.97 \\
(3.52)\end{array}$ & 4.94 \\
\hline $\mathbf{N}$ & 340 & 173 & & 348 & 206 & CONT & $\begin{array}{l}91 \\
\text { ROL }\end{array}$ & 227 & & 253 & 220 & \\
\hline Core & $\begin{array}{c}2.85 \\
(1.48)\end{array}$ & $\begin{array}{c}3.62 \\
(1.24)\end{array}$ & 2.67 & $\begin{array}{c}3.67 \\
(1.32)\end{array}$ & $\begin{array}{c}3.45 \\
(1.33)\end{array}$ & -.85 & $\begin{array}{c}3.39 \\
(1.02)\end{array}$ & $\begin{array}{c}3.88 \\
(0.91)\end{array}$ & 2.42 & $\begin{array}{c}3.71 \\
(1.01)\end{array}$ & $\begin{array}{c}3.96 \\
(1.02)\end{array}$ & 1.36 \\
\hline Level-Specific & $\begin{array}{c}7.32 \\
(2.45)\end{array}$ & $\begin{array}{c}7.24 \\
(2.37)\end{array}$ & -0.16 & $\begin{array}{c}7.68 \\
(2.37)\end{array}$ & $\begin{array}{c}6.62 \\
(2.32)\end{array}$ & -2.30 & $\begin{array}{c}6.10 \\
(1.91)\end{array}$ & $\begin{array}{c}6.24 \\
(2.55)\end{array}$ & 0.31 & $\begin{array}{c}7.86 \\
(2.66)\end{array}$ & $\begin{array}{c}7.79 \\
(2.71)\end{array}$ & -0.14 \\
\hline Total & $\begin{array}{l}10.17 \\
(3.34)\end{array}$ & $\begin{array}{l}10.86 \\
(3.13)\end{array}$ & 1.04 & $\begin{array}{l}11.35 \\
(3.10)\end{array}$ & $\begin{array}{l}10.07 \\
(3.15)\end{array}$ & -2.10 & $\begin{array}{c}9.50 \\
(2.38)\end{array}$ & $\begin{array}{l}10.13 \\
(2.67)\end{array}$ & 1.20 & $\begin{array}{l}11.57 \\
(3.05)\end{array}$ & $\begin{array}{l}11.75 \\
(3.01)\end{array}$ & 0.33 \\
\hline $\mathbf{N}$ & 46 & 50 & & 69 & 42 & & 48 & 45 & & 73 & 52 & \\
\hline
\end{tabular}

t-values test the null hypothesis that post score equals pre score; $(\quad)=$ standard deviations

TABLE 2

CCAI Scores, Mean Correct by Level and Group

\begin{tabular}{|c|c|c|c|c|c|c|c|c|c|c|c|c|}
\hline & \multicolumn{3}{|c|}{ ELEMENTARY I } & \multicolumn{3}{|c|}{ ELEMENTARY II } & \multicolumn{3}{|c|}{ JUNIOR HIGH I } & \multicolumn{3}{|c|}{ JUNIOR HIGH II } \\
\hline & Pre & Post & t-value & Pre & Post & t-value & Pre & Post & t-value & Pre & Post & t-value \\
\hline & \multicolumn{12}{|c|}{ CHOICES \& CHANGES } \\
\hline Core & $\begin{array}{l}10.90 \\
(4.81)\end{array}$ & $\begin{array}{l}15.26 \\
(4.56)\end{array}$ & 9.61 & $\begin{array}{l}13.78 \\
(4.31)\end{array}$ & $\begin{array}{l}15.32 \\
(4.71)\end{array}$ & 3.95 & $\begin{array}{l}15.02 \\
(3.47)\end{array}$ & $\begin{array}{l}16.01 \\
(4.52)\end{array}$ & 2.85 & $\begin{array}{l}15.24 \\
(3.99)\end{array}$ & $\begin{array}{l}16.21 \\
(4.01)\end{array}$ & 2.65 \\
\hline Level-Specific & $\begin{array}{l}15.21 \\
(4.03)\end{array}$ & $\begin{array}{l}17.83 \\
(4.57)\end{array}$ & 6.20 & $\begin{array}{c}4.84 \\
(3.07)\end{array}$ & $\begin{array}{c}5.11 \\
(3.55)\end{array}$ & 0.95 & $\begin{array}{l}11.20 \\
(3.46)\end{array}$ & $\begin{array}{l}12.15 \\
(3.67)\end{array}$ & 3.05 & $\begin{array}{l}10.79 \\
(3.06)\end{array}$ & $\begin{array}{l}11.54 \\
(3.47)\end{array}$ & 2.52 \\
\hline Total & $\begin{array}{c}26.12 \\
(7.45)\end{array}$ & $\begin{array}{l}33.10 \\
(7.54)\end{array}$ & 9.62 & $\begin{array}{l}18.63 \\
(6.34)\end{array}$ & $\begin{array}{c}20.42 \\
(6.82)\end{array}$ & 3.15 & $\begin{array}{l}26.22 \\
(5.76)\end{array}$ & $\begin{array}{l}28.10 \\
(7.19)\end{array}$ & 3.45 & $\begin{array}{c}26.04 \\
(5.97)\end{array}$ & $\begin{array}{l}27.76 \\
(6.55)\end{array}$ & 3.01 \\
\hline $\mathbf{N}$ & 357 & 157 & & 344 & 213 & CONT & $\begin{array}{l}294 \\
\text { ROL }\end{array}$ & 235 & & 259 & 221 & \\
\hline Core & $\begin{array}{l}12.84 \\
(4.18)\end{array}$ & $\begin{array}{l}13.08 \\
(4.33)\end{array}$ & 0.23 & $\begin{array}{l}13.79 \\
(3.95)\end{array}$ & $\begin{array}{l}13.52 \\
(4.78)\end{array}$ & -0.32 & $\begin{array}{l}15.50 \\
(3.49)\end{array}$ & $\begin{array}{l}15.93 \\
(3.23)\end{array}$ & 0.62 & $\begin{array}{c}15.85 \\
(4.33)\end{array}$ & $\begin{array}{l}15.62 \\
(5.27)\end{array}$ & -0.27 \\
\hline Level-Specific & $\begin{array}{l}16.74 \\
(4.16)\end{array}$ & $\begin{array}{l}15.96 \\
(3.58)\end{array}$ & -0.79 & $\begin{array}{c}4.68 \\
(2.34)\end{array}$ & $\begin{array}{c}4.40 \\
(3.20)\end{array}$ & -0.53 & $\begin{array}{l}11.72 \\
(3.50)\end{array}$ & $\begin{array}{l}11.82 \\
(3.51)\end{array}$ & 0.14 & $\begin{array}{l}11.34 \\
(3.59)\end{array}$ & $\begin{array}{l}11.77 \\
(3.90)\end{array}$ & 0.63 \\
\hline Total & $\begin{array}{l}29.58 \\
(7.38)\end{array}$ & $\begin{array}{l}29.04 \\
(7.18)\end{array}$ & -0.30 & $\begin{array}{l}18.48 \\
(4.95)\end{array}$ & $\begin{array}{l}17.93 \\
(6.82)\end{array}$ & -0.49 & $\begin{array}{l}27.23 \\
(5.95)\end{array}$ & $\begin{array}{c}27.76 \\
(5.56)\end{array}$ & 0.45 & $\begin{array}{l}27.18 \\
(7.01)\end{array}$ & $\begin{array}{l}27.39 \\
(8.23)\end{array}$ & 0.15 \\
\hline $\mathbf{N}$ & 50 & 24 & & 69 & 42 & & 48 & 45 & & 71 & 52 & \\
\hline
\end{tabular}

$\mathrm{t}$-values test the null hypothesis that post score equals pre score; $(\quad)=$ standard deviations

Walstad 1987), the following functional relationships were hypothesized:

Student Achievement $=\mathrm{f}$ (Student Attitude, Initial Endowments, Demographic Characteristic, Class Time, Treatment)

Student Attitude = $\mathrm{f}$ (Student Achieve- ment, Initial Endowments, Demographic Characteristics, Teacher Attitude, Treatment)

Given this specification, cognitive and attitudinal response are assumed to be simultaneously formed in a manner similar to that advanced by Grimes, Krehbiel, Nielsen, and Niss (1989). 
Alternatively, Siegfried and Walstad (1990) have argued that the direction of causation runs only one-way; learning influences attitude formation but changes in attitude do not necessitate cognitive response. Although a review of the recent empirical evidence supports this position (Walstad 1987), the simultaneous specification was chosen given that the Choices \& Changes curriculum was intentionally designed with lessons aimed at affecting the students' perception of their role in the economic world around them. Thus, throughout the Choices \& Changes program, economic concepts and ideas are intertwined with important attitudinal concepts such as motivation and self-worth. If the assumed simultaneous relationship between cognitive and affective response is not supported by the empirical results, changes in the relative emphasis of basic economic concepts and attitudinal concepts may be warranted to meet the long-run goals of the program.

The hypothesized determinants of student achievement and attitude in [1] and [2] above represent the generally accepted relationships established by the empirical economics education literature. (Most empirical studies have been modeled after the extensive literature concerning college economics; see Siegfried and Fels (1979) and Siegfried and Walstad (1990).) Initial endowments of economics understanding and personal attitudes represent measures of student ability and aptitude. A range of demographic characteristics, notably gender and race, have in some cases been found to influence achievement and attitude formation. The current model attempts to control for these factors as well as for differences in classroom implementation and teacher satisfaction with the curriculum. Treatment on the right-hand side of [1] and [2] reflects the difference in exposure to the Choices \& Changes curriculum between the experimental and control groups. If Choices \& Changes is effective in meeting its short-run goals, the Treatment term should capture significant differences between the two groups of students.

Based on the functional form specified above and using data collected from the surveyed teachers, the following equations were estimated using 2 SLS for each of the four grade levels:
Post-TOCC $=a+b_{1}$ Post-CCAI $+b_{2}$ Gender

$+b_{3}$ Age $+b_{4}$ Black $+b_{5}$ Hispanic +

$\mathrm{b}_{6}$ Asian $+\mathrm{b}_{7}$ Pre-TOCC $+\mathrm{b}_{8}$ Days +

$b_{9}$ Control + Lambda $+e$

Post-CCAI $=a+c_{1}$ Post-TOCC $+c_{2}$ Gender

$+c_{3}$ Age $+c_{4}$ Black $+c_{5}$ Hispanic

$+\mathrm{c}_{6}$ Asian $+\mathrm{c}_{7}$ Pre-CCAI $+\mathrm{c}_{8}$ Teacher

Satisfaction $+\mathrm{c}_{9}$ Control

+ Lambda $+\mathrm{e}$

Where (expected right-hand signs in parentheses):

a-Estimated intercept term.

Pre-TOCC - Student's pre-course score on the grade specific TOCC. $(+)$

Post-TOCC-Student's post-course score on the grade specific TOCC. (+)

Pre-CCAI-Student's pre-course sore on the grade specific CCAI. (+)

Post-CCAI-Student's post-course score on the grade specific CCAI. (+)

Gender-Categorical variable $=0$ if student is female; $=1$ if male. $(+)$

Age-Student's chronological age in years. $(+1-)$

Black-Percentage of students in classroom who are Black. $(+/-)$

Hispanic-Percentage of students in classroom who are Hispanic. $(+/-)$

Asian-Percentage of students in classroom who are Asian. $(+/-)$

Days-Number of days Choices \& Changes was taught in the student's classroom. (+)

Teacher Satisfaction-Teacher's satisfaction with the Choices \& Changes curriculum; five response categorical variable running from "Very Satisfied" = 1 to "Very Dissatisfied" = 5. (-)

Control-Categorical treatment variable $=1$ if student is in control group; $=0$ if student is in experimental (Choices \& Changes) group. (-)

Lambda-Heckman's self-selection correction term (inverse of Mill's Ratio).

e-Random error term.

The mean and standard deviation for each variable is reported in Table 3. These descriptive statistics are calculated using all observations for which pre-course and post-course data were available. In general, the expected signs express 
TABLE 3

Selected Sample Descriptive Statistics-Means and Standard Deviations

\begin{tabular}{lcccc}
\hline Variable & $\mathrm{E} 1$ & $\mathrm{E} 2$ & $\mathrm{~J} 1$ & $\mathrm{~J} 2$ \\
\hline Pref-Tocc & 8.848 & 10.579 & 9.591 & 11.051 \\
& $(3.168)$ & $(3.286)$ & $(3.635)$ & $(4.906)$ \\
Post-TOCC & 12.754 & 12.276 & 11.781 & 13.508 \\
& $(4.408)$ & $(3.552)$ & $(3.327)$ & $(3.546)$ \\
Pre-CCAI & 26.193 & 18.430 & 24.862 & 23.927 \\
& $(8.373)$ & $(7.015)$ & $(8.163)$ & $(9.896)$ \\
Post-CCAI & 32.538 & 20.733 & 28.037 & 27.927 \\
& $(8.175)$ & $(6.311)$ & $(6.893)$ & $(6.619)$ \\
Gender & 0.485 & 0.502 & 0.435 & 0.492 \\
& $(0.501)$ & $(0.501)$ & $(0.497)$ & $(0.501)$ \\
Age & 9.389 & 11.448 & 13.463 & 15.656 \\
& $(0.552)$ & $(0.789)$ & $(0.837)$ & $(0.962)$ \\
Black & 55.170 & 67.982 & 67.193 & 59.276 \\
& $(35.378)$ & $(23.731)$ & $(33.684)$ & $(33.331)$ \\
Hispanic & 22.725 & 5.186 & 15.569 & 12.742 \\
& $(28.302)$ & $(7.325)$ & $(20.657)$ & $(25.390)$ \\
Asian & 3.807 & 3.303 & 1.130 & 7.076 \\
& $(4.102)$ & $(5.337)$ & $(2.328)$ & $(16.968)$ \\
Teacher Satisfaction & 1.380 & 1.480 & 1.699 & 1.882 \\
& $(0.882)$ & $(0.927)$ & $(1.038)$ & $(0.945)$ \\
Days & 11.205 & 11.040 & 14.506 & 12.061 \\
& $(9.734)$ & $(10.739)$ & $(9.945)$ & $(6.650)$ \\
Control & 0.146 & 0.186 & 0.167 & $(0.397)$ \\
& $(0.389)$ & $(0.389)$ & $(0.374)$ & 262 \\
N & 171 & 221 & 269 & \\
\hline
\end{tabular}

the relationships established in the extensive empirical economics education literature. The indeterminate expected signs on the race and ethnic variables reflect the specification of these variables. Given data collection constraints, these terms measure the racial and ethnic composition of the student's classroom, and not the individual student's race or ethnic heritage. Some studies have shown a negative effect of minority status on economics learning, however, this effect may be nullified the more homogeneous the classroom. Given that the sample is one of at-risk students in urban school districts, the definition "minority" is questionable.

The Lambda term enters the model to control for self-selected loss of data between pre-course and post-course observations. The potential for bias to be introduced into the estimation of educational production functions due to missing post-course observations has been examined in detail by Becker and Walstad (1990). In this case, missing post-course data may be the result of actions by either the student or the student's teacher. Absence from school on the day of the post-test or failure of the student to complete the test would select the students out of the sample. Likewise, failure of the teacher to administer the post-test or to return the post-tests for scoring would select such students in the class out of the sample. The number of post-course observations per grade level ranged from $41 \%$ to $72 \%$ of the pre-course observations (compare the N's in Tables 3 and 4). To control for potential selection bias, the standard Heckman (1979) procedure was employed.

The Heckman procedure requires estimation, using the full sample, of the probability of being included in the final sample (with complete preand post-course data). The probability equation should include additional variables that directly determine selection. The results of this estimation are then used to calculate Lambda which is included in the achievement and attitude equations. Thus, the following equation was estimated by probit to generate the Heckman correction term: 
TABLE 4

Self-Selection Probit Results

\begin{tabular}{lcccc}
\hline Variable & $\mathrm{E} 1$ & $\mathrm{E} 2$ & $\mathrm{~J} 1$ & $\mathrm{~J} 2$ \\
\hline Constant & 1.426 & -0.356 & 6.023 & -0.743 \\
& $(0.832)$ & $(0.327)$ & $(4.583)$ & $(0.476)$ \\
Gender & -0.156 & 0.006 & -0.120 & -0.032 \\
& $(0.832)$ & $(0.042)$ & $(0.759)$ & $(0.190)$ \\
Age & -0.835 & 0.150 & -0.491 & 0.110 \\
& $(5.191)$ & $(1.574)$ & $(5.21)$ & $(1.106)$ \\
Black & 0.047 & -0.010 & 0.014 & $(3.557)$ \\
& $(5.836)$ & $(2.697)$ & 0.028 & $(2.266)$ \\
Hispanic & 0.079 & -0.045 & $(3265)$ & -0.001 \\
& $(6.100)$ & $(1.847)$ & 0.005 & $(0.309)$ \\
Asian & 0.429 & -0.039 & $(0.099)$ & 0.006 \\
& $(6.821)$ & $(4.680)$ & -0.254 & $(1.298)$ \\
At Risk & 1.310 & -5.869 & $(0.515)$ & 1.110 \\
& $(3.099)$ & $(0.020)$ & 1513 & $(4.233)$ \\
Training & -4.163 & 1.317 & $(3.725)$ & -7.431 \\
& $(0.015)$ & $(3.615)$ & -.410 & $(0.025)$ \\
South & 2.250 & -0.767 & $(1.876)$ & 0.683 \\
& $(5.692)$ & $(4.279)$ & 1.046 & $(2.434)$ \\
Control & 4.128 & 0.444 & $(3.341)$ & -1.544 \\
& $(4835)$ & $(1824)$ & .828 & $(5.179)$ \\
Psuedo $\mathrm{R}^{2}$ & .865 & .667 & 90.470 & .848 \\
$X^{2}$ & 333.660 & 186.780 & 373 & 126.070 \\
$\mathrm{~N}$ & 422 & 451 & 361 \\
\hline
\end{tabular}

$(\quad)=$ t-statistics

Inclusion $=\mathrm{a}+\mathrm{d}_{1}$ Gender $+\mathrm{d}_{2}$ Age + $\mathrm{d}_{3}$ Black $+\mathrm{d}_{4}$ Hispanic $+\mathrm{d}_{5}$ Asian + $\mathrm{d}_{6}$ At-Risk $+\mathrm{d}_{7}$ Training $+\mathrm{d}_{8}$ South + $\mathrm{d}_{9}$ Control $+\mathrm{e}$

Where the demographic and treatment variables are as defined above and:

Inclusion-Categorical variable $=1$ if post-course data observed; $=0$ otherwise.

At-Risk-Categorical variable $=1$ if other at-risk programs are being implemented in the classroom; $=0$ otherwise. $(+)$

Training-Number of years the teacher received training and taught the Choices \& Changes curriculum. (+)

South-Categorical variable $=1$ if school district is located in the Southern census region; $=0$ otherwise. $(+/-)$

The demographic variables are included to capture any systematic differences by student groups in selecting into or out of the sample. The At-Risk and Training variables are expected to capture the teacher's commitment to the program and thereby positively influence the teacher to administer and return the post-tests.
South is included to capture any regional differences in the school year and other time constraints that could influence the ability of teachers to administer and return the post-tests.

The probit results are reported in Table 4. Most coefficients display expected signs and many obtain statistical significance. The estimated equations appear to fit the data well with significant Chi-Square statistics and high Pseudo $\mathrm{R}^{2} \mathrm{~s}$ is defined as the percentage of correct predictions estimated by the equation). The four estimated equations were evaluated to calculate Lambda for each observation included in the final sample. If a significant selection process influenced the composition of the final sample, Lambda will enter the achievement and attitude equations with a statistically significant coefficient.

\section{Empirical Results}

The estimated 2SLS results for regression equations [3] and [4] are reported for each grade level in Tables 5 and 6 . In each case, the estimated equation yielded a statistically signif- 
TABLE 5

Estimated Determinants of Cognitive Performance

(Dependent Variable $=$ Post TOCC)

\begin{tabular}{|c|c|c|c|c|}
\hline Variable & El & E2 & $\mathrm{J} 1$ & $\mathrm{~J} 2$ \\
\hline Constant & $\begin{array}{c}-8.415 \\
(1.130)\end{array}$ & $\begin{array}{l}11.850 \\
(3.217)\end{array}$ & $\begin{array}{l}21.848 \\
(2.481)\end{array}$ & $\begin{array}{c}7.927 \\
(2.003)\end{array}$ \\
\hline Post-CCAI & $\begin{array}{c}-0.020 \\
(0.136)\end{array}$ & $\begin{array}{c}0.241 \\
(2.901)\end{array}$ & $\begin{array}{c}0.057 \\
(0.289)\end{array}$ & $\begin{array}{l}0.019 \\
(0.348)\end{array}$ \\
\hline Gender & $\begin{array}{c}-0.839 \\
(1.518)\end{array}$ & $\begin{array}{c}-0.331 \\
(0.867)\end{array}$ & $\begin{array}{c}-0.521 \\
(1.301)\end{array}$ & $\begin{array}{c}-0.058 \\
(0.142)\end{array}$ \\
\hline Age & $\begin{array}{l}1.875 \\
(2.350)\end{array}$ & $\begin{array}{r}-0.542 \\
(1.965)\end{array}$ & $\begin{array}{c}-0.979 \\
(2.844\end{array}$ & $\begin{array}{c}0.241 \\
(1.058)\end{array}$ \\
\hline Black & $\begin{array}{c}0.054 \\
(2.224)\end{array}$ & $\begin{array}{c}-0.005 \\
(0.300)\end{array}$ & $\begin{array}{r}-0.014 \\
(1.512)\end{array}$ & $\begin{array}{c}-0.015 \\
(2.571)\end{array}$ \\
\hline Hispanic & $\begin{array}{c}0.042 \\
(1.471)\end{array}$ & $\begin{array}{c}-0.084 \\
(2.182)\end{array}$ & $\begin{array}{r}-0-019 \\
(1.448)\end{array}$ & $\begin{array}{c}-0.002 \\
(0.336)\end{array}$ \\
\hline Asıan & $\begin{array}{c}-1.105 \\
(4.813)\end{array}$ & $\begin{array}{c}0.089 \\
(1.620)\end{array}$ & $\begin{array}{r}0.055 \\
(0.452\end{array}$ & $\begin{array}{c}0.016 \\
(1.700)\end{array}$ \\
\hline Days & $\begin{array}{c}0.389 \\
(4.205)\end{array}$ & $\begin{array}{c}0.044 \\
(2.142)\end{array}$ & $\begin{array}{c}-0.021 \\
(0.482)\end{array}$ & $\begin{array}{c}-0.032 \\
(0.824)\end{array}$ \\
\hline Pre-TOCC & $\begin{array}{c}0.316 \\
(1.826)\end{array}$ & $\begin{array}{c}0.348 \\
(4.531)\end{array}$ & $\begin{array}{c}0.240 \\
(2.039)\end{array}$ & $\begin{array}{c}0.122 \\
(2.577)\end{array}$ \\
\hline Control & $\begin{array}{r}-4.876 \\
(3.312)\end{array}$ & $\begin{array}{c}-2.523 \\
(3.339)\end{array}$ & $\begin{array}{r}-1.721 \\
(1.865)\end{array}$ & $\begin{array}{c}-4.845 \\
(4.077)\end{array}$ \\
\hline Lambda & $\begin{array}{c}-6.241 \\
(3.329)\end{array}$ & $\begin{array}{c}-3.712 \\
(4.352)\end{array}$ & $\begin{array}{c}3.303 \\
(2.661)\end{array}$ & $\begin{array}{c}5.473 \\
(3.527)\end{array}$ \\
\hline$N$ & .171 & .221 & 2698 & 262 \\
\hline $\begin{array}{l}\mathrm{F} \\
\text { Adj. } R^{2}\end{array}$ & $\begin{array}{l}14.226 \\
438\end{array}$ & 17.060 & $\begin{array}{r}7.524 \\
106\end{array}$ & 5.558 \\
\hline
\end{tabular}

icant F-statistic and an acceptable crosssectional Adjusted $\mathrm{R}^{2}$. Examination of the Adjusted $R^{2}$ values across equations reveals that both the cognitive performance and attitude response equations explain a greater proportion of the observed variation in student scores at the lower grade levels. In fact, the Adjusted $\mathbf{R}^{2}$ values systematically fall across grade levels for both equations. This indicates that unobserved variables outside the model's specification become more important at the higher grade levels. Thus, it appears that the learning and attitude formation processes becomes more complex and therefore more difficult to explain as at-risk students mature and progress through the curriculum.

The estimated sets of cognitive performance and attitude formation equations are separately discussed below. The statistical significance of a regression coefficient was determined using a one-tailed test for variables with an expected sign. A two-tailed test was employed for those with an indeterminate a priori sign. Significant coefficients had to obtain a t-value such that $p<$ .10 or less. (All t-values reported in Tables 5 and 6 are based on standard errors "corrected" for 2SLS bias.)

\section{Cognitive Performance}

Table 5 reveals that the estimated Post-CCAI coefficient is positive, as expected, in three of the four equations. However, it obtains statistical significance in only the Elementary 2 equation. Although such results provide only limited support to the hypothesized simultaneous relationship between cognitive performance and attitude formation, such a relationship cannot be ruled out.

Several interesting relationships between cognitive performance and student characteristics can be found in Table 5. First, the Gender coefficient obtains statistical significance only in the Elementary 1 equation. The predicted male advantage is not found for the latter grade levels. Second, Age is found to be positive and 
TABLE 6

Estimated Determinants of Attitude Response

(Dependent Variable $=$ Post CCAI)

\begin{tabular}{lcccc}
\hline Variable & E1 & E2 & J1 & J2 \\
\hline Constant & 5.813 & 0.761 & 8.532 & 22.088 \\
& $(0.410)$ & $(0.089)$ & $(0.708)$ & $(2.844)$ \\
Post-CCAI & 0.777 & 0.693 & 1.726 & 0.381 \\
& $(1.659)$ & $(2.262)$ & $(4.017)$ & $(1.406)$ \\
Gender & -0.034 & -0.917 & -0.456 & 0.414 \\
& $(0.033)$ & $(1.160)$ & $(0.546)$ & $(0.535)$ \\
Age & 3.672 & 0.290 & -0.417 & -0.437 \\
& $(2.398)$ & $(0.509)$ & $(0.598)$ & $(1.002)$ \\
Black & -0.136 & -0.002 & -0.042 & 0.017 \\
& $(2.370)$ & $(0.059)$ & $(2.305)$ & $(1.604)$ \\
Hispanic & -0.108 & -0.043 & 0.073 & 0.002 \\
& $(1.64)$ & $(0.411)$ & $(2.379)$ & $(0.125)$ \\
Teacher Satisfaction & -0.744 & -0.265 & 0.083 & -0.019 \\
& $(2.406)$ & $(1.579)$ & $(0.370)$ & $(1.043)$ \\
Days & -2.952 & 1.833 & -2.099 & -0.101 \\
& $(1.46)$ & $(1.329)$ & $(4.016)$ & $(0.193)$ \\
Pre-CCAI & 0.264 & 0.293 & 0.081 & 0.246 \\
& $(3.432)$ & $(3.828)$ & $(1.388)$ & $(6.203)$ \\
Control & 2.006 & 2.332 & 1.434 \\
& $(2.781$ & $(0.844)$ & $(1.517)$ & $(0.644)$ \\
Lambda & 2.408 & 5.471 & 1.939 \\
& -13.250 & $(1.407)$ & $(2.089)$ & $(0.623)$ \\
$\mathrm{N}$ & $(3.681)$ & 221 & & 262 \\
$\mathrm{~F}$ & 171 & 8.460 & 6.158 & 5.059 \\
Adj. R & & .253 & .161 & .134 \\
\hline ( & 11.464 & .381 & &
\end{tabular}

( ) $=$ t-statistics

statistically significant (two-tailed t-test) for the Elementary 1 group, but significantly negative in the Elementary 2 and Junior High 1 equations. It is hypothesized that the relatively older students found in the upper grade levels may be those at-risk students who have been "held back" from normal grade level advancement. Thus, the negative relationship between Age and cognitive performance is expected. The racial and ethnic classroom population coefficients reveal mixed results. Positive coefficients are found for the Black and Hispanic variables at the lower grade levels while negative coefficients are reported for these variables at the higher grade levels. Just the opposite pattern is found for the Hispanic variable. The effect of a classroom's racial and ethnic composition appears to be sensitive to the racial or ethnic group in question and the grade level of the class.

The student's initial endowment of economic knowledge as measured by the Pre-TOCC coefficient is found to be positive and statistically significant for all grade levels. The
Pre-TOCC is found to have its largest impact on the Elementary 2 group. The Days coefficient reflects the effect of classroom instruction time on cognitive performance. Days is found to be positive and significant in the two Elementary equations but not in the Junior High Equations. More mature students are apparently less sensitive to the length of classroom instruction.

The Control coefficients reported in Table 5 are of primary importance because they reflect the estimated difference in Post-TOCC scores between the Choices \& Changes students and the control group students. For each grade level, the Control coefficients are found to be negative and statistically significant at normally acceptable levels. This indicates that students exposed to the Choices \& Changes programs outperformed the control students and the cognitive performance gains were not random. The largest estimated effects of the program on Post-TOCC scores are found in the Elementary 1 and Junior High 2 groups. Such results indicate that the Choices \& Changes curriculum is meeting its 
first goal-effective delivery of basic economic education to at-risk student populations.

It should be noted that the self-selection term, Lambda, enters each of the four equations with a statistically significant coefficient. Interestingly, Lambda is negative for the Elementary grade levels and positive for the Junior High grade levels. A negative Lambda implies that without correcting for self-selection, the regression equation would have led to an overestimation of predicted Post-TOCC scores. Thus, students with a "weaker" academic performance were selected out of the Elementary samples. By similar reasoning, students with a "stronger" academic performance were selected out of the Junior High samples. Why the selection process varies between the Elementary and Junior High school samples is not readily apparent. However, it is most likely due to institutional factors and time constraint differences experienced by the teachers who administered the testing process.

\section{Attitude Formation}

As reported in Table 6, the Post-TOCC coefficient is positive and statistically significant in each of the four attitude equations. Thus, cognitive performance in economics appears to strongly affect student attitudes concerning their role in the economy. This result, within the framework of the 2SLS model, provides support for the hypothesized simultaneous relationship between cognitive and affective outcomes. However, when the Post-TOCC results in the attitude equations are compared to the PostCCAI results in the performance equations, the combined findings suggest that the effect of learning on attitudes is stronger than the effect of attitudes on learning.

Gender and Age are not found to be important determinants of attitude formation. Each of the Gender coefficients are insignificant and Age is significantly different from zero only in the Elementary 1 equation. Again, the race and ethnic variables yield mixed results. The only clear pattern in the race and ethnic coefficients is an estimated negative effect at the younger grade levels. The greater the proportion of traditional minorities in elementary classrooms, the smaller the predicted attitude score. Thus, there is evidence to suggest that it may be more difficult to affect attitudinal changes for these groups.

Based on the estimated Pre-CCAI coefficients, a student's initial attitude score is a strong predictor of their post-course attitude score. In each of the four equations the Pre-CCAI coefficient is positive and significant. Teacher Satisfaction, a measure of the teacher's attitude toward the curriculum, is found to be important in determining student attitudes in the Elementary 1 and Junior High 1 groups. Teachers expressing lesser degrees of satisfaction with the Choices \& Changes curriculum are found to have a negative impact on student attitude scores in those two grade levels.

Again, the Control coefficients are of primary concern because they reflect the estimated difference in post-course attitude scores between the treatment and control groups. As seen in Table 6, only in the Elementary 1 equation does Control obtain a significant and negative coefficient as expected. This indicates that Choices \& Changes had a significant impact on attitude formation for Elementary 1 students, ceteris paribus. However, significant differences are not found for the three remaining grade levels. Although the Choices \& Changes students at these grade levels exhibited significant improvements between Pre-CCAI and Post-CCAI scores (see Table 2), when all else is controlled for no significant difference is found between the treatment and control groups. This set of results is consistent with the hypothesis that it is easier to affect attitudinal change among younger at-risk students relative to their older counterparts. The life-experiences of older-at-risk students may create substantial barriers to curriculums designed to improve attitudinal formation.

Lastly, with respect to the results reported in Table 6, Lambda again demonstrates a shift in sign between the Elementary and Junior High School levels. The self-selection correction term is positive and significant in the Elementary 1 equation and negative and significant in the Junior High 1 equation. These results parallel those found in the estimated cognitive performance equations.

\section{Conclusions}

Choices \& Changes has been consciously designed to help students who are at-risk in our 
public schools. By promoting economic knowledge and understanding, the program is intended to elicit positive student attitudes about themselves and their role in the economy. These student outcomes should be translated into positive behavioral responses in the future. This first in-depth study of the program has addressed the effect of Choices \& Changes on student learning and attitudes - two of the program's primary objectives.

Using a national sample of at-risk students and test instruments designed to capture student understanding of basic economic concepts, an educational production function estimated by 2SLS revealed positive and statistically significant improvements in student performance after exposure to Choices \& Changes, ceteris paribus.

The empirical results also indicate that Choices \& Changes has a positive and statistically significant effect on student attitudes at the lowest grade level examined. The two-stage model did not reveal significant differences in attitude formation between the control and treatment groups in the higher grade levels. These findings suggest that it is possible to alter the attitudes of young at-risk children through economic education, but additional intervention may be required for older students. This conclusion does not imply that the Choices \& Changes program is failing to meet one of its primary objectives. The program is designed as a multi-grade curriculum whereby at-risk students are exposed to economic education throughout several years of their basic education. In this initial evaluation, students took part in only one year of the program. The attitude response observed at the Elementary 1 level should be reinforced and enhanced as those students again experience Choices \& Changes in later years.

One may hypothesize that the relatively larger cognitive and attitudinal improvements for the elementary students is found because intervention is more effective with younger students who are more receptive to new ideas. However, the results may also indicate that the Choices \& Changes curricula for the elementary grades is stronger than those or the junior high school grades, or that the elementary teachers were more motivated, more conscientious, or better prepared to teach the lessons. Additional information and testing is needed to address these issues. Longitudinal databases that track students as they progress through each grade level of Choices \& Changes will need to be constructed in order to address the long-run effects of the program. Further, researchers must be able to identify objective measures of behavioral response if they are to evaluate the ultimate success of the program.

Based on the results presented here, the Choices \& Changes program appears to be meeting its short-run cognitive and attitudinal objectives. The ultimate test of Choices \& Changes is how well the cognitive and attitudinal responses documented here are translated into future behavioral responses. This study has taken only the first step in evaluating the effect of economic education on the at-risk student population. Additional and more sophisticated analyses are needed to determine the long-run influence of economic education on individual at-risk students. 


\section{APPENDIX}

The following six questions are the core questions included in each version of the TOCC. These questions concern major cognitive concepts common to the curriculum at all grade levels of Choices \& Changes. 14 level-specific questions comprise the rest of each TOCC. Students are asked to choose the best response.

1. A teacher has five movie tickets to give her students. What is most scarce?
A. Teachers.
B. Movies.
C. Tickets.
D. Make a choice.

2. After school a friend asks you to play basketball. Another friend wants you to watch television. You have a lot of homework. What must you do first?
A. Play basketball.
B. Watch television.
C. Do your homework.
D. Make a choice.

3. On her way to school, Alicia spends her lunch money buying candy. What is Alicia's opportunity cost?
A. Lunch.
B. The price of the candy.
C. Going to school.
D. Going to the candy store.

4. Jim wants to be a good cook. He is taking cooking lessons. Jim is improving his
A. capital
B. human resources
C. opportunity costs
D. alternative choices

5. Instead of going out with her friends, Jane stayed home and studied for her math test. Jane got a high score on the test. Why did Jane earn a better score on the test than her friends?
A. Because Jane made a different choice than her friends made.
B. Because she must not be going out with her friends.
C. Because Jane likes math.
D. Because her friends are dumb.

6. Marcus just graduated from high school. What can Marcus choose to become?
A. A worker providing services
B. A worker making goods.
C. A worker selling goods and services.
D. A worker of any kind.

The following eight statements are the core statements included in each version of the CCAI. These statements concern major attitude themes common to the curriculum at all grade levels of Choices \& Changes. Six level-specific statements comprise the rest of each CCAI. Students asked to respond on a five point scale running from "Strongly Disagree" (1) to "Strongly Agree" (5).

1. I can make choices.

2. I am a worker.

3. I am not part of the economy.

4. Education improves my skills and knowledge.

5. I am important.

6. I do not have control over may life.

7. Success in life usually comes from being lucky.

8. I can make plans and set goals. 


\section{References}

Becker, W. E. and W. B. Walstad, eds. 1987. Econometric Modeling in Economic Education Research. Boston: Kluwer-Nijhoff.

Becker, W. E., and W. B. Walstad. 1990. "Data loss from Pretest to Posttest as a Sample Selection Problem." Review of Economics and Statistics 72 (February): 184-188.

Bloom, B. S., ed. 1956. Taxonomy of Educational Objectives: The Classification of Educational Goals, Handbook 1: Cognitive Domain. New York: McKay Publishing.

Gilliard, J. V., J. Caldwell, et. al. 1988. Economics: What and When, Scope and Sequence Guidelines, $K-12$. New York: National Council on Economic Education.

Grimes, P. W. 1991. Cognitive and Attitudinal Effects for At-Risk Students Enrolled in Choices \& Changes. New York: National Council on Economic Education.

Grimes, P. W., T. L. Krehbiel, J. Nielsen, and J. Niss. 1989. "The Effectiveness of Economics U\$A on Learning and Attitudes. Journal of Economic Education 20 (Spring): 139-152.
Heckman, J. 1979. "Sample Bias as a Specification Error." Econometrica 47 (January:: 153-162.

National Council on Economic Education. 1989. Choices \& Changes Teacher Training Handbook. New York: Joint Council on Economic Education. Siegfried, J. J. and R. Fels. 1979. "Research on Teaching College Economics: A Survey." Journal of Economic Literature 17 (September): 923-969.

Siegfried, J. J. and W. B. Walstad. 1990. "Research on Teaching College Economics." In P. Saunders and W. B. Walstad, eds., The Principles of Economics Course: A Handbook for Instructors. New York: McGraw-Hill.

Soper, J. and W. B. Walstad. 1983. "On Measuring Economic Attitude." Journal of Economic Education 14, (Fall): 4-18.

Walstad, W. B. 1987. “Applying Two-Stage Least Squares -." In Becker, W. E. and W. B. Walstad. Econometric Modeling in Economic Education Research. Boston: Nijhoff Publishing. 111-134.

Walstad, W. B. and D. Robson. 1990, Basic Economics Test Examiner's Manual, 2nd Education. New York: National Council on Economic Education. 